\title{
Subtemporal approach to basilar tip aneurysm with division of posterior communicating artery: Technical note
}

\author{
Shunsuke Kakino \\ Kuniaki Ogasawara \\ Yoshitaka Kubo \\ Hideaki Nishimoto \\ Akira Ogawa \\ Department of Neurosurgery, \\ Iwate Medical University School of \\ Medicine, Morioka, Iwate, Japan
}

\begin{abstract}
The subtemporal approach with division of the posterior communicating artery (PcomA) is described for treating aneurysms of the basilar tip. When the ipsilateral posterior cerebral artery (PCA) interferes with visibility and manipulation around the aneurysm neck and the artery is tethered by the PcomA and not mobilized, the PcomA can be divided near the junction with the PCA. The procedure permits PCA mobilization and exposes the neck of the aneurysm. We applied this procedure to a patient with a ruptured aneurysm of the basilar tip. The postoperative course was uneventful except for transient left oculomotor nerve palsy. Postoperative cerebral angiography and magnetic resonance imaging confirmed the respective disappearance of the aneurysm and no new ischemic lesions. The subtemporal approach allows safer and easier division of the PcomA near the junction to the PCA compared with the pterional approach, and the present procedure is more suitable for the subtemporal approach.
\end{abstract}

Keywords: basilar tip aneurysm, subtemporal approach, posterior communicating artery

\section{Introduction}

The surgical treatment of basilar tip aneurysms remains one of the most difficult tasks in neurosurgery because the view is obscured due to the depth of the aneurysm, overlapping neurovascular and bony structures, and the proximity of perforators. The subtemporal approach to treat distal basilar artery aneurysms was introduced by Drake and colleagues (Hernesniemi et al 1992; Drake et al 1996) and is popular in many centers (Dorsch 1988; Mizoi et al 1994; Hernesniemi et al 2005a, 2005b). During this approach, the ipsilateral posterior cerebral artery (PCA) sometimes interferes with visibility and manipulation around the aneurysm neck (Peerless et al 1995; Hernesniemi et al 2005b).

We describe the subtemporal approach with division of the posterior communicating artery (PcomA) to facilitate exposure of the aneurysm and present our experience of a patient with a ruptured basilar tip aneurysm who was treated with this technique.

\section{Method}

The patient undergoes a fronto-temporal craniotomy in the lateral position. The zygoma is then exposed and partially resected. Under the operating microscope, the temporal lobe is retracted to expose the free margin of the tentorium. The arachnoid overlying the perimesencephalic cistern is incised and cerebrospinal fluid is aspirated.

The PCA runs immediately in front of the neck of a basilar tip aneurysm (Figure 1A) and posterior manipulation of the PCA is necessary to fully expose the aneurysm. However, the PCA is tethered by the PcomA and is not mobilized. Firstly, the PcomA is coagulated near the junction to the PCA using bipolar forceps to avoid injuring the perforating arteries originating from the PcomA (Figure 1B). The coagulated PcomA is trapped with two Sugita AVM microclipsR (Mizuho Medical, Tokyo, Japan) and 

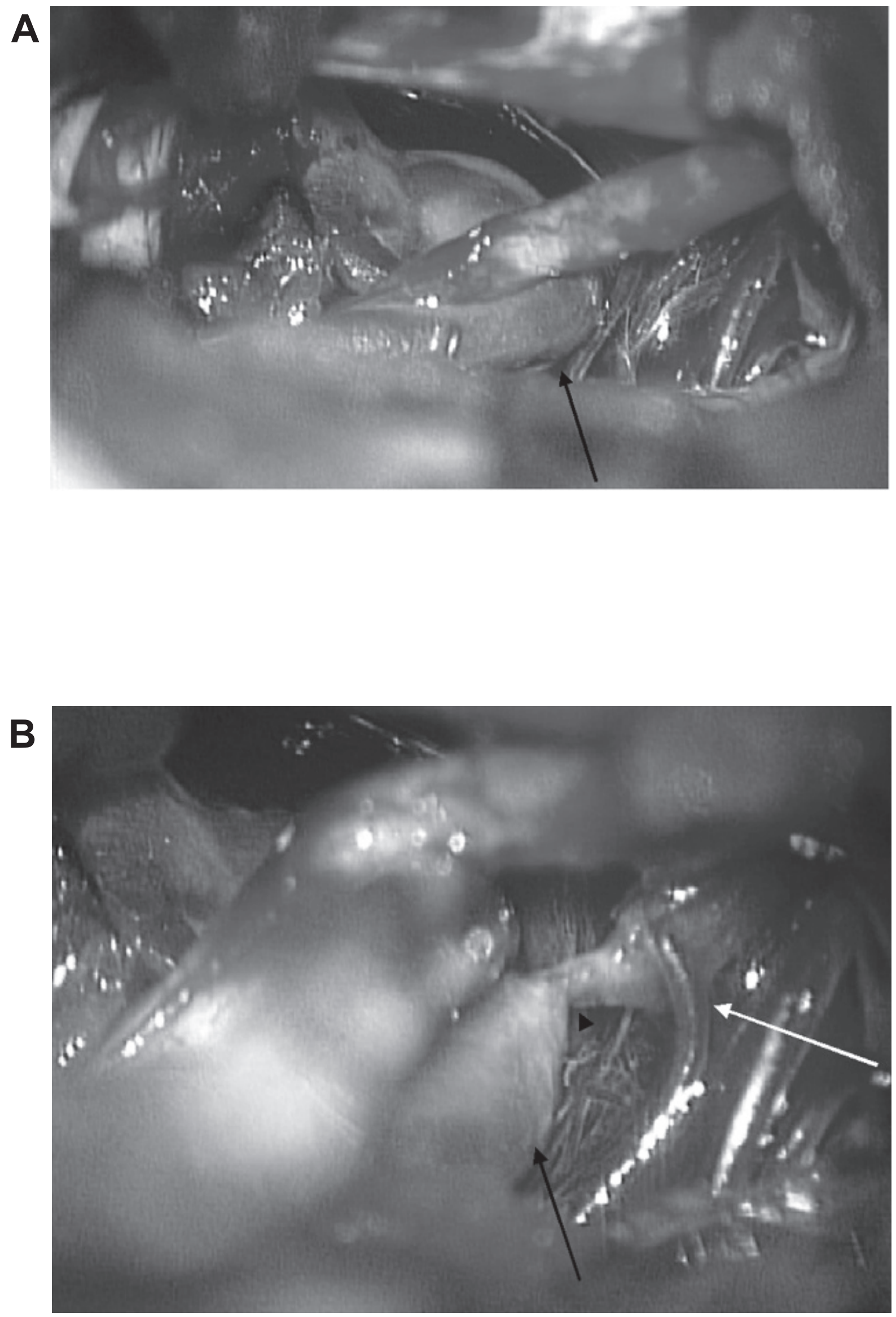

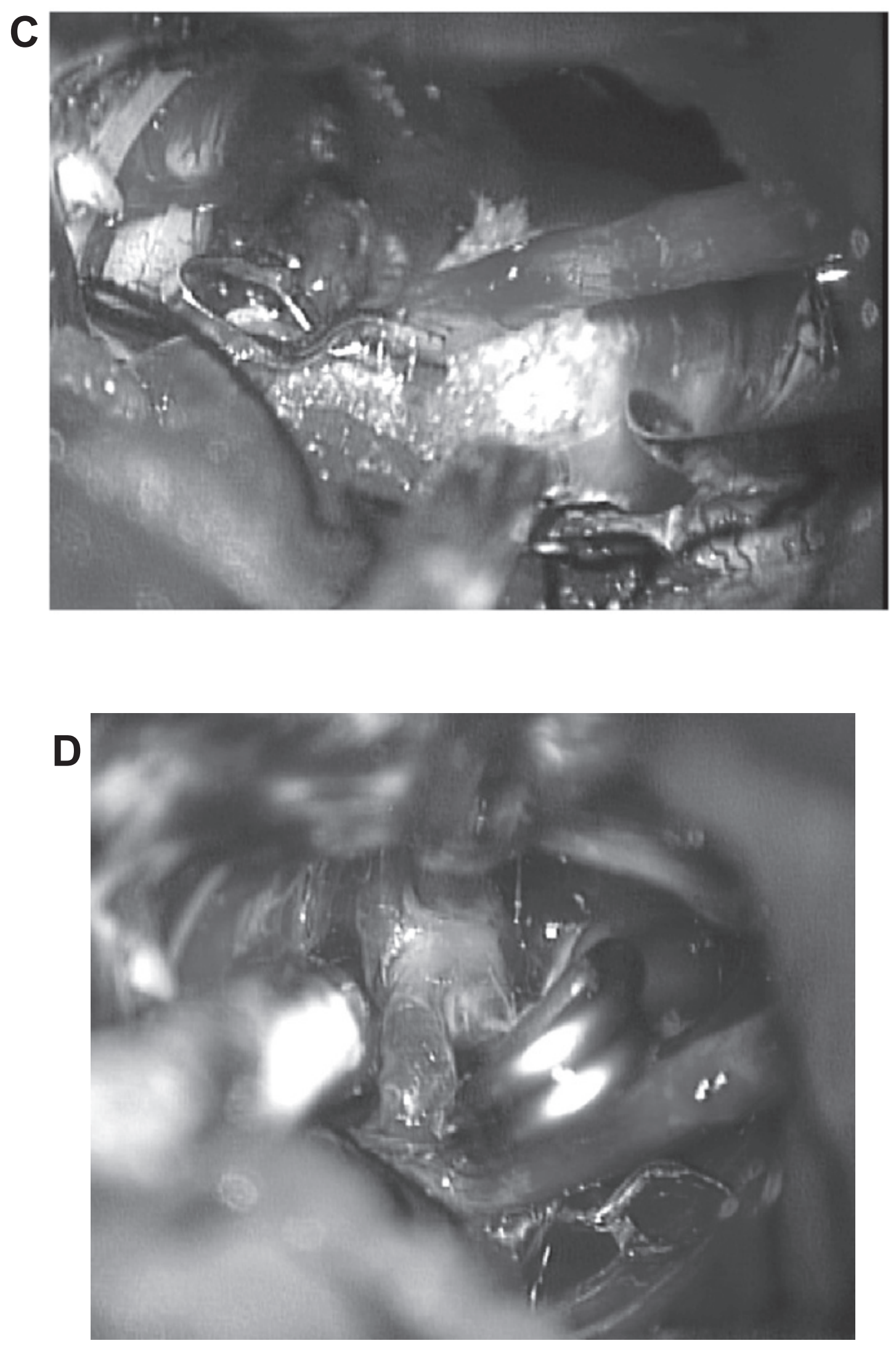

Figure I Intraoperative findings. A: Left posterior cerebral artery (black arrow) runs just in front of neck of basilar tip aneurysm. B: Left posterior communicating artery (arrow head) is coagulated near the junction to the left posterior cerebral artery (black arrow) using bipolar forceps. Perforating artery originating from posterior communicating artery is visible (open arrow). C: Left posterior communicating artery is divided and aneurysm is widely exposed. Two clips applied before division of posterior communicating artery are visible. $\mathbf{D}$ : Aneurysm is clipped at the neck. 
cut between the two clips (Figure 1C). Thus, the PCA is posteriorly mobilized and the neck of the basilar tip aneurysm is exposed, allowing easy clipping of the aneurysm (Figure 1D).

We applied this technique in a 41-year-old woman who presented with a subarachnoid hemorrhage. The vertebral angiogram showed an aneurysm (maximum diameter of $10 \mathrm{~mm}$ ) located at the basilar bifurcation as high as the posterior clinoid process (Figure 2). The patient underwent craniotomy on the day following the onset of subarachnoid hemorrhage when she exhibited headache without any neurological deficits. A left subtemporal approach was selected because the left PCA was lower than the right, and the aneurysm was directed slightly towards the left. Because the diameter of the left PcomA was smaller than that of the left PCA, the aneurysm was clipped using the described technique. Transient left oculomotor nerve palsy occurred postoperatively. Postoperative cerebral computed tomography and magnetic resonance imaging confirmed the respective disappearance of the aneurysm and no new ischemic lesions.

\section{Discussion}

In the pterional approach, division of the PcomA permits a shift of the PCA to the dorsal side and greater retraction of the internal carotid artery, which exposes aneurysms of the basilar tip (Fox 1983; Yasargil et al 1976; Yasargil 1984; Rhoton 2002). The procedure is also useful in the subtemporal approach when the PCA runs just in front of a basilar tip aneurysm and needs to be posteriorly manipulated to fully expose the neck of the aneurysm.

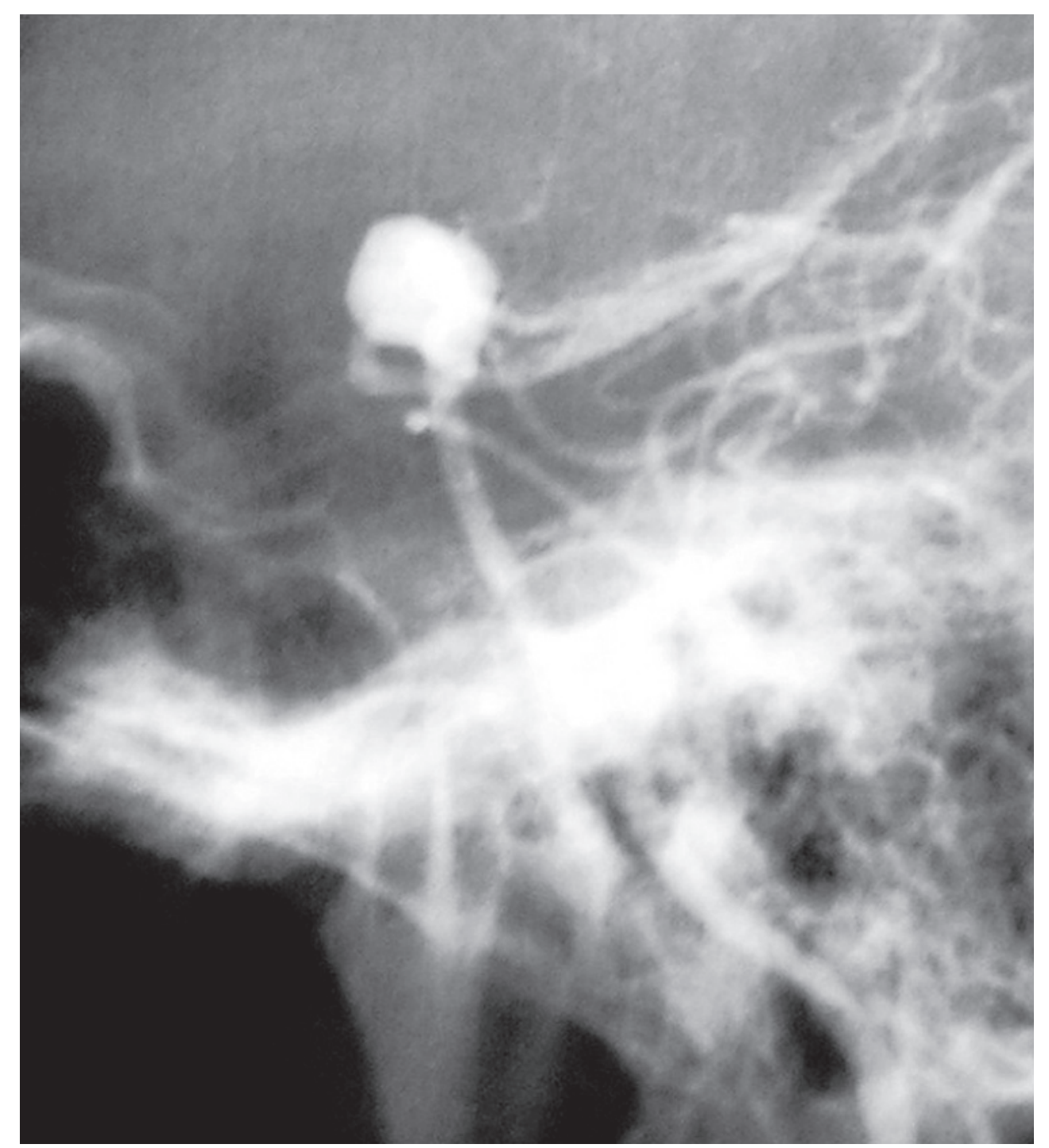

Figure 2 Lateral view of left vertebral angiogram demonstrating aneurysm (maximum diameter of $10 \mathrm{~mm}$ ) located at the basilar bifurcation as high as the posterior clinoid process. 
Many authors have agreed that the safety of the procedure is related to preservation of perforating arteries originating from the PcomA (Yasargil 1984; Regli and de Tribolet 1991; Inao et al 1996; Nukui et al 1998; Tanaka et al 1998). Anatomical studies have shown that perforators along the course of the posterior half of the PcomA arise less often than those of the anterior half and have smaller diameters (Inao et al 1996; Gabrovsky 2002). The premamillary artery, which is the largest branch arising from the PcomA, rarely emerges in the posterior third of the PcomA (Gabrovsky 2002). The diameter of PcomA at the PCA junction is smaller than that at the carotid junction (Saeki and Rhoton 1977). Moreover, the normal direction of flow in the PcomA is thought to be from the internal carotid artery (ICA) (Schomer et al 1994). Thus, a PcomA division near the PCA would be safer, and preserve normal flow to the perforators, unlike sectioning near the ICA (Inao et al 1996; Gabrovsky 2002).

In the subtemporal approach, the posterior half of the PcomA and the branches originating from the portion are clearly visible and the PcomA can be safely and easily divided near the junction with the PCA compared with the pterional approach. Thus, the present procedure is more suitable for the subtemporal approach.

While the surgical clippings for basilar tip aneurysms are often chosen in Japan (Nukui et al 1998), the treatment for such aneurysms trend toward the endovascular method in Europe (Henkes et al 2005) and US (Tateshima et al 2000). Because long-term outcomes of patients with cerebral aneurysms who were treated with endovasucular approach remain unknown (Molyneux et al 2002), we usually choose a surgical clipping through craniotomy for patients less than 60 years.

\section{References}

Dorsch NW. 1988. Aid to exposure of the upper basilar artery: technical note. Neurosurgery, 23:790-1.

Drake C, Peerless S, Hernesniemi J. 1996. Surgery of Vertebrobasilar Aneurysms. London, Ontario Experience on 1767 Patients. 1st ed. Vienna: Springer-Verlag, 1:21-7.

Fox J. 1983. Technique of Aneurysm Surgery. V. Basilar Artery Aneurysms. In: Intracranial Aneurysms. New York, NY: Springer-Verlag, 2:1024-69.
Gabrovsky N. 2002. Microanatomical bases for intraoperative division of the posterior communicating artery. Acta Neurochir (Wien), 144:1205-11.

Henkes H, Fischer S, Mariushi W, et al. 2005. Angiographic and clinical results in 316 coil-treated basilar artery bifurcation aneurysms. J Neurosurg, 103:990-9.

Hernesniemi J, Ishii K, Karatas A, et al. 2005a. Surgical technique to retract the tentorial edge during subtemporal approach: technical note. Neurosurgery, 57(4 Suppl):E408; discussion E.

Hernesniemi J, Ishii K, Niemela M, et al. 2005b. Subtemporal approach to basilar bifurcation aneurysms: advanced technique and clinical experience. Acta Neurochir Suppl, 94:31-8.

Hernesniemi J, Vapalahti M, Niskanen M, et al. 1992. Management outcome for vertebrobasilar artery aneurysms by early surgery. Neurosurgery, 31:857-61; discussion 61-2.

Inao S, Kuchiwaki H, Hirai N, et al. 1996. Posterior communicating artery section during surgery for basilar tip aneurysm. Acta Neurochir (Wien), 138:853-61.

Mizoi K, Yoshimoto T, Takahashi A, et al. 1994. Direct clipping of basilar trunk aneurysms using temporary balloon occlusion. J Neurosurg, 80:230-6.

Molyneux A, Kerr R, Stratton I, et al. 2002. International Subarachnoid Aneurysm Trial (ISAT) of neurosurgical clipping versus endovascular coiling in 2143 patients with ruptured intracranial aneurysms: a randomised trial. Lancet, 360:1267-74.

Nukui H, Mitsuka S, Hosaka T, et al. 1998. Technical points to improve surgical results in cases with basilar tip aneurysms. Neurol Med Chir (Tokyo), 38(Suppl):74-8.

Peerless S, Hernesniemi J, Drake C. 1995. Surgical management of terminal basilar and posterior cerebral artery aneurysms. In: Schmidek H, Sweet W (eds). Operative Neurosurgical Techniques. ed 3rd. Philadelphia, PA: W.B. Sauders Company, 1:1071-86.

Regli L, de Tribolet N. 1991. Tuberothalamic infarct after division of a hypoplastic posterior communicating artery for clipping of a basilar tip aneurysm: case report. Neurosurgery, 28:456-9.

Rhoton AL, Jr. 2002. Aneurysms. Neurosurgery, 51(4 Suppl)S121-58.

Saeki N, Rhoton AL, Jr. 1977. Microsurgical anatomy of the upper basilar artery and the posterior circle of Willis. J Neurosurg, 46:563-78.

Schomer DF, Marks MP, Steinberg GK, et al. 1994. The anatomy of the posterior communicating artery as a risk factor for ischemic cerebral infarction. $N$ Engl J Med, 330:1565-70.

Tanaka Y, Kobayashi S, Kyoshima K, et al. 1998. Factors influencing surgical outcome of the basilar bifurcation aneurysms. Neurol Med Chir (Tokyo), 38(Suppl):79-82.

Tateshima S, Murayama Y, Gobin YP, et al. 2000. Endovascular treatment of basilar tip aneurysms using Guglielmi detachable coils: anatomic and clinical outcomes in 73 patients from a single institution. Neurosurgery, 47:1332-9; discussion 9-42.

Yasargil MG. 1984. Basilar artery bifurcation aneurysms, In: Yasargil MG (ed). Microsurgery. New York, NY: Georg Thieme Verlag, 2:233-56.

Yasargil MG, Antic J, Laciga R, et al. 1976. Microsurgical pterional approach to aneurysms of the basilar bifurcation. Surg Neurol, 6:83-91. 
